\title{
Gestational obesity and risk of hypospadias in male newborns. A population based case-control study ${ }^{*}$
}

\author{
Tariq O. Abbas, Mansour Ali, Ashraf A. Ibrahim
}

Pediatric Surgery Department, Hamad General Hospital, Doha, Qatar

Email: tariq2c@,hotmail.com

Received 1 November 2013; revised 25 November 2013; accepted 2 December 2013

Copyright (C 2013 Tariq O. Abbas et al. This is an open access article distributed under the Creative Commons Attribution License, which permits unrestricted use, distribution, and reproduction in any medium, provided the original work is properly cited.

\begin{abstract}
Aim: Hypospadias is a relatively common male genital anomaly that may be caused by anomalies in maternal hormone levels and/or blood glucose levels as well as nutritional deficiencies. Maternal obesity, which increases the risk of diabetes, may alter hormone levels, and may thereby be associated with risk of hypospadias. This study was designed to determine the impact of these risk factors on hypospadias in boys born at the largest tertiary hospital in Qatar. Methods: This population-based, case-control study used linked birth-hospital discharge data from Hamad General Hospital in Doha, Qatar, from January 2007 to December 2012. Boys with hypospadias were identified, and risk factors were determined. Adjusted odds ratios (aORs) and 95\% confidence intervals (CIs) for hypospadias were estimated by multivariable logistic regression models adjusted for maternal age, parity and body mass index (BMI). Results: Seventy-three newborn male infants with hypospadias and 100 without the condition, with birth weight above $2500 \mathrm{~g}$, were compared. Maternal obesity (BMI $\left.\geq 30 \mathrm{~kg} / \mathrm{m}^{2}\right)$ was not associated with risk of hypospadias (aOR 1.07; 95\% 0.95 - 1.21), and no trend in risk with increasing maternal BMI was observed. Conclusion: Although the causes of male genital malformation are multifactorial, the present data do not support the hypothesis that gestational maternal obesity is a cause of hypospadias in male infants.
\end{abstract}

\section{Keywords: Maternal Obesity; Hypospadias; Genital}

\footnotetext{
"Authors' Contributions: TA was responsible for most of the proposal writing, data analysis and manuscript writing. MA participated in manuscript structuring. AA participated in the planning and manuscript design. Funding: this work was supported by the Medical Research Centre of Hamad Medical Corporation, Qatar (MRC Proposal \# 12242/12). Institutional Ethics Committee: approved by Medical Research Centre, Hamad Medical Corporation 3050, Doha, Qatar, Tel: 0097444392440.
}

Birth Defects

\section{INTRODUCTION}

Birth defects occur in approximately $3 \%$ of all live births and are a major contributing factor to infant mortality and childhood and adult disability [1,2]. Evaluation of trends in the prevalence of birth defects and their distribution among subpopulations can help public health professionals and care providers better evaluate potential clusters, conduct etiologic and outcome research, determine health services needs, and target health care.

Hypospadias is the most common congenital anomaly of the penis. The condition is characterized by a urethral meatus that is ectopically located proximal to the normal location on the ventral aspect of the penis. It is the second most common genital abnormality (after cryptorchidism) in male newborns, with incidence rates in different series ranging between $0.3 \%$ and $0.8 \%$ [3]. Other anomalies that may accompany hypospadias include meatal stenosis, hydrocele, and cryptorchidism (in $8 \%$ to $10 \%$ of cases). When complications occur, the resultant morbidity of corrective procedures, psychological stress, and potential loss of function can be devastating to the patient and family.

Over the past two decades, concerns have been raised over possible increases in disorders of the male reproductive tract, including cryptorchidism, hypospadias, testicular cancer, and impaired semen quality. These disorders may be interrelated and share a common etiology during fetal life, described as the testicular dysgenesis syndrome (TDS) [4].

Although hypospadias is one of the most common congenital abnormalities, its etiology is not yet completely understood. Androgens, including dihydrotestosterone (DHT), have been shown to play an important role in normal testicular descent and the development of external male genitalia. Mutations in the AR gene and in the gene encoding 5-alpha-reductase type II, responsible 
for the conversion of testosterone to DHT, have been associated with undescended testis(-es) and/or hypospadias. These mutations, however, are extremely rare and are very unlikely to be responsible for the ethnic gradient in the occurrence of TDS. No association has been found between CAG repeat length in the AR gene and any of these congenital male genital abnormalities. In contrast, the length of the GGN trinucleotide repeat in the AR gene has been found to differ in Swedish men with penile hypospadias or a history of cryptorchidism and healthy Swedish men [5]. In a few cases, maternal exposure to progestin during gestational weeks $8-14$ has been found to cause hypospadias [6].

Studying such interactions has biological and public health-related implications. Such studies will assist in understanding the background for defects in male reproductive organs, facilitate the proper design of epidemicological studies and contribute to the identification of individuals susceptible to certain environmental and lifestyle related hazards.

At least three potential mechanisms may relate maternal obesity to risk of hypospadias. Levels of circulating hormones, including androgens, differ between obese and normal-weight mothers [7-12]. Lower overall diet quality and blood concentrations of micronutrients have also been observed in obese women and may be related to the risk of birth defects such as hypospadias, although findings are inconsistent [13-16]. Finally, impaired fasting glucose and glucose tolerance before and during pregnancy have been associated with obesity, $[17,18]$ and uncontrolled glucose concentrations have been associated with birth defects [13]. The present study assessed whether maternal obesity is a risk factor for hypospadias in males newly born at Hamad Medical Center, the only tertiary hospital in Qatar.

\section{METHODS}

This nested case-control study involved a large cohort of boys born at Hamad General Hospital in Doha, Qatar, from 2002 to 2012. Case subjects were defined as male singleton infants with an ICD-10 code for hypospadias (752.61). Hypospadias (anterior, middle and posterior) was defined as a displacement of the urethral meatus from the tip of the glans penis to the ventral side of the phallus, scrotum, or perineum. Only infants with hypospadias were included; those with ambiguous genitalia without further description were excluded, as were infants with recognized gene disorders or chromosomal abnormalities.

Data were summarized on a standardized questionnaire entered into an electronic database and checked for accuracy, with both data extraction and entry performed by the same investigator. Maternal data included demographic characteristics (age, parity, and BMI), and re- productive characteristics (parity, usage of contraceptive pills, assisted reproductive techniques). Infant characteristics included sex, birth weight, gestational age, family history, type of hypospadias and subsequent procedures. BMI $\left(\mathrm{kg} / \mathrm{m}^{2}\right)$ was categorized according to the World Health Organization guidelines as underweight (BMI < $18.5 \mathrm{~kg} / \mathrm{m}^{2}$ ), normal weight (BMI $18.5-24.9 \mathrm{~kg} / \mathrm{m}^{2}$ ), overweight (BMI $25.0-29.9 \mathrm{~kg} / \mathrm{m}^{2}$ ), and obese classes I (BMI $30.0-34.9 \mathrm{~kg} / \mathrm{m}^{2}$ ), II (BMI $35.0-39.9 \mathrm{~kg} / \mathrm{m}^{2}$ ), and III (BMI $\geq 40.0 \mathrm{~kg} / \mathrm{m}^{2}$ ).

Control subjects were randomly selected from the remaining male singleton infants, at a ratio of 1 control subject per case subject and frequency-matched to case subjects according to year of birth. One hundred healthy male newborns without hypospadias or micropenis, matched for parity (primiparous), twin birth, gestational age ( \pm 1 week) and date of birth ( \pm 7 days).

This study was approved by the institutional review board of Hamad General Hospital, Doha.

The main exposure variables obtained from birth certificates were maternal age, race/ethnicity, and diabetes status (none, preexisting or gestational). Missing data were not included in the analyses. Other potential confounding variables considered were maternal prenatal smoking (yes, no, or missing), number of prior births and pregnancies, the gestational age and weight (grams, as a continuous variable) of the child, and use of assisted reproductive techniques (yes or no).

Crude yearly birth prevalence rates were determined by dividing the total number of males with hypospadias born during a calendar year by the total number of male singleton births during the same year.

\section{Statistical Analysis}

Descriptive statistics were used to summarize the demographic characteristics of patients. Mean $( \pm$ standard deviation) are reported where appropriate. The associations between hypospadias and potential risk factors were assessed and reported as crude ORs and 95\% CIs. Subsequently, logistic regression analysis was performed.

\section{RESULTS}

The study subjects included 73 newborn males with hypospadias and 97 normal (control) male newborns. Mean body weight at birth was lower in newborns with than without hypospadias $(3096 \pm 823 \mathrm{~g}$ vs $3283 \pm 583 \mathrm{~g})$. Almost equal percentages of boys with hypospadias were born of primiparous mothers and those of other parities (Table 1), and $4.1 \%$ were products of twin or triplet pregnancies. Infants with hypospadias were slightly more likely to be delivered at gestational age $<37$ weeks, and their mothers were slightly less likely to have had prior births (Table 1). Most other characteristics were similar 
in the case and control groups.

The risk of hypospadias did not increase with increasing maternal age, with ORs ranging from 1.95 (95\% CI; $0.37-10.20)$ for infants of mothers aged 20 to 24 years to 0.46 (95\% CI: 0.03 - 6.89) for infants of mothers aged $>40$ years (Table 2). However, placental weight $<600 \mathrm{~h}$ was slightly more common (OR 1.77 ; 95\% CI 0.66 4.80), and placental weight $600-700 \mathrm{~g}$ slightly less common (OR 0.76 ; 95\% CI 0.35 - 1.65) in newborns with than without hypospadias, although the differences were not statistically significant.

Infants born to underweight, overweight or obese mothers were not at higher risk of hypospadias than infants born to normal-BMI mothers. When the BMIs of these mothers BMIs were divided into three categories, $<25,25-35$ and $>35 \mathrm{~kg} / \mathrm{m}^{2}$, the risk estimates for the latter two groups, with ORs of 1.09 (95\% CI, 0.36 - 3.29) and $1.11(95 \% \mathrm{CI}, 0.33-3.80)$, were compared with the first group (Table 2).

\section{DISCUSSION}

Hypospadias is the second most common genital abnormality (after cryptorchidism) in male newborns, with an incidence in ranging between $0.3 \%$ and $0.8 \%$ [3]. The incidence of hypospadias has increased in European and

Table 1. Maternal reproductive factors in newborn males with and without hypospadias.

\begin{tabular}{cccc}
\hline \multicolumn{2}{c}{ Characteristic } & Hypospadias N (\%) & Control N (\%) \\
\hline $\begin{array}{c}\text { Prior } \\
\text { pregnancies }\end{array}$ & 1 & $15(20.5 \%)$ & $15(15.5 \%)$ \\
& 3 or more & $45(61.8 \%)$ & $62(63.9 \%)$ \\
& 0 & $17(23.2 \%)$ & $20(20.6 \%)$ \\
Prior births & 1 & $16(21.9 \%)$ & $27(27.8 \%)$ \\
& 2 & $18(24.7 \%)$ & $15(15.5 \%)$ \\
& 3 or more & $22(30.2 \%)$ & $35(36.1 \%)$ \\
Gestational & Less than 37 & $15(20.5 \%)$ & $6(6.2 \%)$ \\
age, wk & $38-42$ & $38(52.1 \%)$ & $90(92.8 \%)$ \\
& More than 42 & $20(27.4)$ & $1(1 \%)$ \\
\hline
\end{tabular}

Table 2. Relationship between maternal BMI and risk of hypospadias in newborn males

\begin{tabular}{lcccc}
\hline & & $\begin{array}{c}\text { Hypospadias } \\
\text { patients }\end{array}$ & Controls & OR (95\%CI) \\
\hline & Less than 25 & $7(11.3 \%)$ & $10(11.2 \%)$ & 1.00 (referent) \\
$\mathrm{BMI}$, & $25-35$ & $39(62.9 \%)$ & $61(68.5 \%)$ & $1.09(0.36-3.29)$ \\
$\mathrm{kg} / \mathrm{m}^{2}$ & & & & \\
& More than 35 & $16(25.8 \%)$ & $18(20.2 \%)$ & $1.11(0.33-3.80)$ \\
\hline
\end{tabular}

American countries, doubling from 1970 to 1993 [19]. Hypospadias may be in part a genetic condition. For example, studies have reported that $7 \%-9 \%$ and $11 \%$ of fathers having sons with hypospadias had hypospadias themselves [20]. Moreover, a positive family history of hypospadias was significant, as $44 \%$ of neonates had a family history of this condition [6].

Documenting racial/ethnic differences in the prevalence of hypospadias is critical for determining variations in diagnosis and risk factors among these groups. These racial/ethnic variations in the prevalence of birth defects may result from differences in access to early and highquality prenatal care, which may lead to different patterns of prenatal diagnosis and pregnancy termination. Alternatively, variations in prevalence may reflect different genetic or environmental risk factors. In some surveillance systems, variation by race/ethnicity may also reflect differential ascertainment and diagnosis of patients postnatally [21].

Familial hypospadias may result from a polygenic mode of inheritance. Mild hypospadias (glandular to penile), occurring without other genital abnormalities or dysmorphic features, is very unlikely to be associated with an identifiable endocrinopathy, intersex problem or chromosomal abnormality. The risks of these problems in males with severe hypospadias (penoscrotal or perineal), however, are approximately $15 \%$ [3].

Older maternal age, white race, and preexisting diabetes have been associated with increased risk of hypospadias among male offspring [22]. Although maternal BMI has been associated with the risk of hypospadias, this risk was found to vary, depending on maternal age and the number of previous births, and was strongest among older, first time mothers [23]. A larger study based on Swedish birth records, hospital data, and birth defects registry found that the risk of hypospadias was $\sim 30 \%$ higher in boys born to obese than normal weight mothers, with the difference being statistically significant [23-25]. A smaller study, combining Swedish and Danish clinical and administrative sources, and relying on selfreported pre-pregnancy weight, estimated that the OR for hypospadias was 2.6-fold higher for obese than for normal-BMI mothers [26].

In contrast, we observed at most a small difference in the risks of hypospadias and cryptorchidism among groups of mothers categorized by BMI. Moreover, our estimates of aOR were accompanied by wide CIs, suggesting that any difference may reflect a chance finding.

Since hypospadias is an anomaly of the external genitalia, it may remain hidden in some cultures like Qatar. Thus, family history may be difficult to determine and accuracy may be reduced.

Our reliance on hospital discharge data may have resulted in some underreporting of hypospadias, although 
the use of these data allowed a longer window of observation for birth conditions and anomalies that might not be reported on birth certificates alone. Even birth defect registries may not identify milder forms of hypospadias [20].

Nevertheless, the strength of this retrospective study was its analysis of data from the only tertiary care facility in the country that thoroughly investigated and documented all males born with hypospadias. Case specificity was likely high, and clinical presentation, treatment outcomes, and epidemiology are likely an accurate representation of hypospadias in the population in Qatar.

\section{CONCLUSION}

In conclusion, although the causes of male genital malformation are multifactorial, our findings do not support the hypothesis that gestational maternal obesity is a cause of hypospadias in male infants.

\section{REFERENCES}

[1] Petrini, J., Damus, K., Russell, R., Poschman, K., Davidoff, M.J. and Mattison, D. (2002) Contribution of birth defects to infant mortality in the United States. Teratology, 66, S3-S6. http://dx.doi.org/10.1002/tera.90002

[2] (2008) Update on overall prevalence of major birth defects-Atlanta, Georgia, 1978-2005. Morbidity and Mortality Weekly Report (MMWR), 57, 1-5.

[3] Palmert, M.R. and Dahms, W.T. (2006) Abnormalities of sexual differentiation. In: Fanaroff, A., Martin, R.J. and Walsh, M.C., Eds., Neonatal-Perinatal Medicine Diseases of the Fetus and Infant, 8th Edition, Mosby, Philadelphia, 1565-1566.

[4] Pierik, F.H., Burdorf, A., Deddens, J.A., Juttmann, R.E. and Weber, R.F. (2004) Maternal and paternal risk factors for cryptorchidism and hypospadias: A case-control study in newborn boys. Environmental Health Perspectives, 112, 1570-1576. http://dx.doi.org/10.1289/ehp.7243

[5] Rylander, L., Hagmar, L. and Giwercman, Y.L. (2006) Ethnic differences in occurrence of TDS genetics and/or environment? International Journal of Andrology, 29, 291297; discussion 304-306. http://dx.doi.org/10.1111/j.1365-2605.2005.00621.x

[6] Mohammadzadeh, A., Farhat. A., Esmaieli, H. and Shiranzaei, S. (2011) Prevalence and risk factors of hypospadias in a private hospital in northeast Iran. Iranian Journal of Pediatrics, 21, 497-501.

[7] Blouin, K., Boivin, A. and Tchernof, A. (2008) Androgens and body fat distribution. The Journal of Steroid Biochemistry and Molecular Biology, 108, 272-280. http://dx.doi.org/10.1016/j.jsbmb.2007.09.001

[8] Jansson, N., Nilsfelt, A., Gellerstedt, M., Wennergren, M., Rossander-Hulthen, L., Powell, T.L. and Jansson, T. (2008) Maternal hormones linking maternal body mass index and dietary intake to birth weight. American Journal of
Clinical Nutrition, 87, 1743-1749.

[9] Morisset, A.S., Blouin, K. and Tchernof, A. (2008) Impact of diet and adiposity on circulating levels of sex hormonebinding globulin and androgens. Nutrition Reviews, 66, 506-516. http://dx.doi.org/10.1111/j.1753-4887.2008.00083.x

[10] Pasquali, R. and Gambineri, A. (2006) Metabolic effects of obesity on reproduction. Reproductive BioMedicine Online, 12, 542-551. http://dx.doi.org/10.1016/S1472-6483(10)61179-0

[11] Pasquali, R., Patton, L. and Gambineri, A. (2007) Obesity and infertility. Current Opinion in Endocrinology, Diabetes, and Obesity, 14, 482-487. http://dx.doi.org/10.1097/MED.0b013e3282f1d6cb

[12] Wei, S., Schmidt, M.D., Dwyer, T., Norman, R.J. and Venn, A.J. (2009) Obesity and menstrual irregularity: Associations with SHBG, testosterone, and Insulin. Obesity, 17, 1070-1076. http://dx.doi.org/10.1038/oby.2008.641

[13] Carmichael, S.L., Rasmussen, S.A. and Shaw, G.M. (2010) Prepregnancy obesity: A complex risk factor for selected birth defects. Birth Defects Research Part A: Clinical and Molecular Teratology, 88, 804-810. http://dx.doi.org/10.1002/bdra.20679

[14] Carmichael, S.L., Yang, W., Correa, A., Olney, R.S. and Shaw, G.M. (2009) Hypospadias and intake of nutrients related to one-carbon metabolism. Journal of Urology, 181, 315-321, discussion 321. http://dx.doi.org/10.1016/j.juro.2008.09.041

[15] Goh, Y.I., Bollano, E., Einarson, T.R. and Koren, G. (2006) Prenatal multivitamin supplementation and rates of congenital anomalies: A meta-analysis. Journal of $\mathrm{Ob}$ stetrics and Gynaecology, 28, 680-689.

[16] Ormond, G., Nieuwenhuijsen, M.J., Nelson, P., Toledano, M.B., Iszatt, N., Geneletti, S. and Elliott, P. (2009) Endocrine disruptors in the workplace, hair spray, folate supplementation, and risk of hypospadias: Casecontrolm study. Environmental Health Perspectives, 117, 303-307.

[17] Chu, S.Y., Callaghan, W.M., Kim, S.Y., Schmid, C.H., Lau, J., England, L.J. and Dietz, P.M. (2007) Maternal obesity and risk of gestational diabetes mellitus. Diabetes Care, 30, 2070-2076. http://dx.doi.org/10.2337/dc06-2559a

[18] Siega-Riz, A.M. and King, J.C. (2009) Position of the American Dietetic Association and American Society for Nutrition: Obesity, reproduction, and pregnancy outcomes. Journal of the American Dietetic Association, 109, 918927. http://dx.doi.org/10.1016/j.jada.2009.03.020

[19] Leung, A.K. and Robson, W.L. (2007) Hypospadias: An update. Asian Journal of Andrology, 9, 16-22.

[20] Carmichael, S.L., Shaw, G.M., Nelson, V., Selvin, S., Torfs, C.P. and Curry, C.J. (2003) Hypospadias in California: Trends and descriptive epidemiology. Epidemiology, 14, 701-706. http://dx.doi.org/10.1097/01.ede.0000091603.43531.d0

[21] Kucik, J.E., Alverson, C.J., Gilboa, S.M. and Correa, A. (2012) Racial/ethnic variations in the prevalence of selected major birth defects, metropolitan Atlanta, 19942005. Public Health Reports, 127, 52-61. 
[22] Porter, M.P., Faizan, M.K., Grady, R.W. and Mueller, B.A. (2005) Hypospadias in Washington State: Maternal risk factors and prevalence trends. Pediatrics, 115, e495e499. http://dx.doi.org/10.1542/peds.2004-1552

[23] Carmichael, S.L., Shaw, G.M., Laurent, C., Olney, R.S. and Lammer, E.J. (2007) Maternal reproductive and demographic characteristics as risk factors for hypospadias. Paediatric and Perinatal Epidemiology, 21, 210-218. http://dx.doi.org/10.1111/j.1365-3016.2007.00809.x

[24] Blomberg, M.I. and Kallen, B. (2010) Maternal obesity and morbid obesity: The risk for birth defects in the offspring. Birth Defects Research. Part A, Clinical and Mo- lecular Teratology, 88, 35-40.

[25] Waller, D.K., Shaw, G.M., Rasmussen, S.A., Hobbs, C.A., Canfield, M.A., Siega-Riz, A.M., Gallaway, M.S. and Correa, A. (2007) Prepregnancy obesity as a risk factor for structural birth defects. Archives of Pediatrics and Adolescent Medicine, 161, 745-750. http://dx.doi.org/10.1001/archpedi.161.8.745

[26] Akre, O., Boyd, H.A., Ahlgren, M., Wilbrand, K., Westergaard, T., Hjalgrim, H., Nordenskjold, A., Ekbom, A. and Melbye, M. (2008) Maternal and gestational risk factors for hypospadias. Environmental Health Perspectives, 116, 1071-1076. http://dx.doi.org/10.1289/ehp.10791 